原著

\title{
脳出血におけるてんかん発作の危険因子
}

\author{
大友智, 荒井 啓晶, ${ }^{1}$ 下田 由輝 ${ }^{1,2}$ 富永 悌二 ${ }^{2}$
}

\section{Risk Factors of Epileptic Seizures in Patients with Intracerebral Hemorrhage}

\author{
Satoru Ohtomo, M.D., Ph.D. ${ }^{1}$, Hiroaki Arai, M.D., Ph.D. ${ }^{1}$, Yoshiteru ShImoda, M.D., Ph.D. ${ }^{1,2}$, \\ and Teiji Tominaga, M.D., Ph.D. ${ }^{2}$
}

${ }^{1}$ Department of Neurosurgery, South Miyagi Medical Center, Miyagi, and ${ }^{2}$ Department of Neurosurgery, Tohoku University Graduate School of Medicine, Sendai, Miyagi, Japan

Summary: Background and Purpose: Spontaneous intracerebral hemorrhage (ICH) can induce epileptic seizures. This study aimed to identify the incidence and risk factors of seizures in patients with ICH. We also investigated whether surgical intervention for hematoma was correlated with the occurrence of seizures.

Methods: A total of 478 adult patients (237 males, 241 females; age 23-101 years) enrolled in this study. Sixty-nine patients underwent removal of hematoma by craniotomy or stereotactic aspiration. Univariate and multivariate logistic regression analyses were used to assess the association of clinical factors with epileptic seizures.

Results: Seizures occurred in 26 (5.4\%) patients with ICH, including early seizures (within 7 days of ICH) in 13 and late seizures (occurring $>7$ days after ICH) in 13. Univariate analysis revealed that hematoma in any lobe was significantly correlated with seizures. Multivariate analysis revealed that hematomas in the frontal lobe (odds ratio [OR]: 11.15; 95\% confidence interval [CI]: 2.94-42.24; $\mathrm{p}=$ 0.0004), temporal lobe (OR: 3.49; 95\% CI: 1.23-9.89; $\mathrm{p}=0.0187$ ), and occipital lobe (OR: $6.41 ; 95 \% \mathrm{CI}$ : $1.48-27.83 ; \mathrm{p}=0.0131$ ) were significantly correlated with seizures. Surgical intervention for hematoma was not associated with seizures. Eleven (84.6\%) of 13 patients with late seizures went on to experience recurrent seizures, in contrast to only 2 (15.4\%) of 13 with early seizures.

Conclusions: Cortical involvement of ICH was a risk factor of seizures. Surgical intervention for ICH did not influence occurrence of seizures. Late seizures are liable to recurrence, are compatible with unprovoked seizures, and may be diagnosed as epilepsy after a first seizure.

\author{
Key words: \\ - intracerebral hemorrhage \\ $\cdot$ seizure \\ - removal of hematoma
}

Surg Cereb Stroke

(Jpn) 46: 200-204, 2018

\section{はじめに}

脳出血に合併するてんかん発作は，大脳皮質を含む出血 例に多く，4-16\%の発生率と報告されている ${ }^{1116)}$ 。脳卒中 治療ガイドライン 2015 年版では, 脳出血の慢性期治療と
して，手術例以外では抗てんかん薬の予防的使用は根拠が ないので勧められないと記載されている ${ }^{15)}$. しかしなが ら, 実際に脳出血の手術治療とてんかん発症について検討 した報告は少ない. 今回, 脳出血後のてんかん発作に関与 する影響を出血部位別に検討し, さらに血腫除去術が発作

みやぎ県南中核病院 脳神経外科, ${ }^{2}$ 東北大学大学院医学系研究科 神経外科学分野(受稿日 2017. 8. 12)(脱稿日 2017. 11. 7)〔連絡先： T 989-1253 宮城県柴田郡大河原町字西 38-1 みやぎ県南中核病院 脳神経外科 大友 智] [Address correspondence: Satoru OHTOMO, M.D., Ph.D., Department of Neurosurgery, South Miyagi Medical Center, 38-1 Aza-nishi, Ohgawara-machi, Shibata-gun, Miyagi 989-1253, Japan] 
の危険因子になり得るか否か検討を行った。 また, 脳出血 発症からてんかん発作初発までの時間により早期発作と晚 期発作に分け，おのおのの違いについても検討を行った.

\section{対象・方法}

当院脳神経外科で急性期治療を行った成人の非外傷性脳 出血例を対象とした．脳動静脈奇形や海綿状血管腫などの 血管奇形による出血例, 出血性梗塞例, 腫瘍内出血例は対 象から除外した. また, 当院退院時点で死亡した症例も除 外した．以上の基準により，478 例 (男性 237 例，女性 241 例）を対象症例とした. 年齢は 23-101 歳, 平均 69.4 歳で あった. 発作は臨床的発作 (clinical seizure) で判定した. 抗てんかん薬の予防的投与は行わず, 臨床的発作が確認さ れた場合に薬物治療を開始した。

出血発症時の頭部 CT より判定した出血の進展部位, 年 齢, 性別, 血腫除去術の有無について, てんかん発作と関 連があるか統計学的解析を行った. 血腫除去術は 69 例で 施行した. 脳卒中治療ガイドラインに準じ ${ }^{15} 2$ 人以上の脳 神経外科専門医の合意で手術適応を決定, 開頭術もしくは 定位的手術を症例に応じて選択した，統計学的解析は logistic regression analysis を用いて単変量解析と多変量解 析を施行, $\mathrm{p}<0.05$ を統計学的有意と判定した.

脳出血発症からてんかん発作初発までの時間により, 発 症 7 日以内の発作を早期発作 (early seizure), 発症 7 日以 降の発作を晚期発作 (late seizure) に分類し ${ }^{1) 12}$ ， おのおの の違いについても検討を行った.

\section{結 果}

てんかん発作は 26 例 (5.4\%)で認めた。主な発作型は, けいれん性の単純部分発作 (simple partial seizure：SPS), 複雑部分発作 (complex partial seizure：CPS), 二次性全 般化発作を含む全身性強直間代発作 (generalized tonicclonic seizure：GTCS)であった.けいれん性発作を呈し

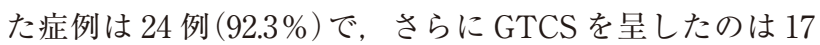
例 (65.4\%) であった。非けいれん性てんかん発作 (non-convulsive seizure：NCS）のみを呈した症例は 2 例 $(7.7 \%)$ で あった. 血腫除去術後にてんかん発作を認めたのは 7 例で あった(Table 1).

単変量解析では, 大脳皮質のいずれかの領域に及ぶ出血 が, てんかん発作と有意に相関が認められた，多変量解析 では, 前頭葉〔odds ratio(OR): 11.15; 95\% confidence interval (CI): 2.94-42.24; $\mathrm{p}=0.0004$ ], 側頭葉 (OR: 3.49; $95 \%$ CI: 1.23-9.89; p=0.0187), 後頭葉 (OR: 6.41; 95\% CI: 1.4827.83; $\mathrm{p}=0.0131$ )のいずれかに及ぶ出血が, てんかん発作 と有意に相関が認められた。血腫除去術施行の有無は, て んかん発作と有意な相関は認めなかった(Table 2).
早期発作を認めたのは 13 例で, 12 例では脳出血発症と 同時に発作が初発した。この 12 例は全例でけいれん性発 作を呈し，10例はGTCSを呈した。発作の反復は 2 例 (15.4\%) でのみ認められた。晚期発作を認めたのは 13 例 で, 12 例では脳出血発症から 2 年以内に発作が初発し た、けいれん性発作を呈したのは 12 例であった。発作の 反復は 11 例 (84.6\%)で認められた (Table 1, 3).

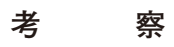

\section{1. てんかん発作の危険因子}

大脳皮質に及ぶ出血は，てんかん発作の危険因子といえ る。これまでの報告でも脳出血で同様の指摘がされてお $り^{2(4) 667)(9) 11161617)}$, 脳梗塞においても大脳皮質の梗塞巣が発 作に関与すると指摘されている(24)9111). 今回われわれは, 出血部位をさらに細分類して詳細な検討を行った．大脳皮 質のいずれかの領域に出血が及んだ場合に，てんかん発作 の危険因子となり得るが, 特に前頭葉, 側頭葉, 後頭葉で その傾向が強いと考えられた，本研究では，出血部位が複 数箇所に及ぶ症例は重複している。これまでは, 症例ごと に大脳皮質に及ぶ出血とそれ以外に分類し, 出血部位と症 例数が一致するように解析した報告がほとんどであっ $た^{(6) 1317)}$. 脳葉を細分類して単葉例と多葉例で解析した報 告もあるが，早期発作のみの検討で症例数が少ないため脳 葉間の差異を示すまでいたっていない2)．実際には，被殼 出血とされた症例でも前頭葉や側頭葉に出血が及ぶ場合が あり，出血部位を大脳皮質とそれ以外に二分類できないこ ともある。本研究でも被殼から大脳皮質に血腫が進展した 4 例でてんかん発作を認めたが, 大脳皮質に進展しにくい 深部の視床や脳幹部出血例では発作合併例は認めなかった (Table 1，2）．血腫の進展部位を細分類することで，発作 の危険因子をより明確にすることができたと考える.

血腫除去術は，てんかん発作の危険因子とはならないと 考えられる。手術治療まで含めて解析した報告は少な く，脳室ドレナージ術やシャント術も含めての報告だ が19)20)，われわれと同様の結果が示されている，手術治療 例では，保存療法例よりも血腫が大きく重症度が高くなっ ている可能性があり得る，過去の報告では，血腫が大きい 場合 ${ }^{13) 17200)}$ や重症度が高(場合 ${ }^{6) 13) 177}$ に発作の危険因子にな り得るとするものと，血腫の大きさ ${ }^{4) 6}$ や重症度 ${ }^{1920)}$ は関連 がないとするものがある，今回は，血腫の大きさと重症度 は検討していないが，これらの因子が手術治療に寄与する 影響も考慮して検討する方法も考えられる。また，手術治 療後に発作を合併した症例が少ないため, 今回は開頭術と 定位的手術の差異を示すまではいたらず，今後のさらなる 検討が必要である．脳卒中後のてんかん発作に対して抗て んかん薬予防投与のエビデンスは確立されておらず, 術後 
Table 1 Summary of patients with seizures

\begin{tabular}{|c|c|c|c|c|c|c|}
\hline \multirow{2}{*}{ Age/ sex } & \multirow{2}{*}{ Lesion } & \multirow{2}{*}{$\begin{array}{c}\text { Hematoma } \\
\text { removal }\end{array}$} & \multicolumn{2}{|c|}{ Clinical seizures } & \multirow{2}{*}{$\begin{array}{c}\text { Seizure onset } \\
\text { after } \mathrm{ICH}\end{array}$} & \multirow{2}{*}{$\begin{array}{c}\text { Recurrent } \\
\text { seizures }\end{array}$} \\
\hline & & & Early & Late & & \\
\hline $81 / \mathrm{M}$ & $\mathrm{T}, \mathrm{O}$ & - & GTCS & & 0 day & - \\
\hline $73 / \mathrm{M}$ & $\mathrm{P}, \mathrm{O}$ & - & GTCS & & 0 day & - \\
\hline $82 / \mathrm{M}$ & $P$ & - & GTCS & & 0 day & - \\
\hline $61 / \mathrm{M}$ & $\mathrm{F}$ & - & GTCS & & 0 day & - \\
\hline $82 / \mathrm{M}$ & $\mathrm{F}$ & - & GTCS & & 0 day & - \\
\hline $58 / \mathrm{M}$ & $\mathrm{P}, \mathrm{O}$ & - & GTCS & & 0 day & - \\
\hline $65 / \mathrm{M}$ & $P$ & - & GTCS & & 0 day & - \\
\hline $87 / F$ & $\mathrm{~T}, \mathrm{O}$ & - & Vocalization-sGTCS & & 0 day & - \\
\hline $95 / F$ & $\mathrm{~F}, \mathrm{~T}$ & - & Convulsion-sGTCS & & 0 day & - \\
\hline $74 / F$ & $\mathrm{~T}, \mathrm{P}$ & - & Convulsion-adversive sz. & & 0 day & - \\
\hline $80 / F$ & $\mathrm{~F}$ & - & Convulsion & & 0 day & - \\
\hline $59 / \mathrm{M}$ & $\mathrm{P}, \mathrm{O}$ & - & Convulsion-sGTCS & & 0 day & + \\
\hline $74 / F$ & $\mathrm{~F}$ & - & Cons. loss (NCS) & & 7 days & + \\
\hline $74 / \mathrm{M}$ & $\mathrm{P}, \mathrm{O}$ & - & & Convulsion & 2 months & + \\
\hline $82 / F$ & $\mathrm{~F}$ & - & & Convulsion-sGTCS & 2 months & + \\
\hline $53 / \mathrm{M}$ & $\mathrm{T}$ & + & & Aphasia-CPS-sGTCS & 3.5 months & + \\
\hline $77 / F$ & $\mathrm{~T}, \mathrm{P}$ & - & & Adversive sz.-tonic sz. & 4 months & + \\
\hline $86 / F$ & $\mathrm{~F}$ & - & & Convulsion-CPS-sGTCS & 4.5 months & + \\
\hline $82 / F$ & $\mathrm{~F}$ & - & & Aphasia-CPS (NCS) & 6 months & - \\
\hline $52 / F$ & $F, T, P$ & + & & GTCS & 9.5 months & - \\
\hline $61 / F$ & F, T, put & + & & GTCS & 10 months & + \\
\hline $56 / F$ & F, put & + & & Tonic sz.-adversive sz. & 1.3 years & + \\
\hline $63 / F$ & $F, P$ & + & & Convulsion-CPS & 1.3 years & + \\
\hline $53 / F$ & F, T, put & + & & Convulsion-sGTCS & 1.4 years & + \\
\hline $59 / F$ & F, put & + & & Convulsion-sGTCS & 1.5 years & + \\
\hline $69 / \mathrm{M}$ & $\mathrm{T}, \mathrm{P}, \mathrm{O}$ & - & & Convulsion-CPS & 2.3 years & + \\
\hline
\end{tabular}

F: frontal lobe, ICH: intracerebral hemorrhage, T: temporal lobe, P: parietal lobe, O: occipital lobe, put: putamen, GTCS: generalized tonic-clonic seizure, sGTCS: secondary GTCS, sz.: seizure, CPS: complex partial seizure, NCS: non-convulsive seizure

の抗てんかん薬投与については症例に応じて慎重な検討を 要すると考えられる.

\section{2. てんかん発作型の問題と脳波}

今回, NCSのみを呈した症例はごくわずかであった. けいれん性 SPS や GTCS は, 自覚的, 他覚的にも認識し やすく発見が容易である。これに対してNCSは，けいれ んを伴わないSPS や軽微な CPS のみである場合があり, 臨床症状から診断することが難しい，診断には脳波が必要 になるが，標準的な 1 回の脳波検查だけでは棘波などのて んかん性放電 (epileptic discharge)を認めない場合も多 く ${ }^{14)}$, 正確な評価には長時間の持続脳波モニタリング (continuous electroencephalographic monitoring : cEEG) が望ましい5)。これまで $\mathrm{cEEG}$ 所見から明確な臨床症状を 伴わない脳波上のみのてんかん発作 (electrographic seizure）を認める例があり，予後不良と関連があったと報告
がある ${ }^{519)}$. 今回はcEEG を施行していないため, electrographic seizure やNCS が見逃されている可能性は否定で きず，今後のさらなる検討が必要である.

\section{3. 早期発作 (early seizure)}

早期発作を認めた症例において，92.3\%が脳出血発症と 同時に発作を認めた。早期発作は脳出血発症から 3 日以内 に認めることが多く ${ }^{13)}$, 特に出血発症と同時に発作 (onset seizure）を認めることが多( ${ }^{6) 11}$ との報告があり同様の傾 向が示された。

早期発作は，晚期発作 (late seizure) の危険因子とする 報告と ${ }^{13)}$ ，そうではないとする報告 ${ }^{817)}$ の両者があり，必 ずしも一定の見解が得られていない. Biffi ら ${ }^{3)}$ は脳出血後 に新たに発症した late seizure を delayed seizure とし, 早 期発作が晚期に反復した発作 (recurrent late seizure) と区 別して検討したところ, delayed seizureは機能転帰不良 
Table 2 Result of univariate and multivariate logistic regression analyses for clinical factors correlated with seizures

\begin{tabular}{|c|c|c|c|c|}
\hline & \multicolumn{2}{|c|}{ Seizures } & \multirow{2}{*}{$\begin{array}{c}\text { Univariate } \\
p\end{array}$} & \multirow{2}{*}{$\begin{array}{c}\text { Multivariate } \\
\mathrm{p}\end{array}$} \\
\hline & Yes $(n=26)$ & No $(n=452)$ & & \\
\hline Age, years (mean $\pm S D$ ) & $70.7 \pm 12.3$ & $69.4 \pm 13.6$ & 0.6235 & 0.4809 \\
\hline Sex, female & $15(57.7 \%)$ & $226(50.0 \%)$ & 0.4471 & 0.6752 \\
\hline Lobar hematoma & $26(100.0 \%)$ & $61(13.5 \%)$ & & \\
\hline Frontal lobe & $14(53.8 \%)$ & $28(6.2 \%)$ & $<0.0001^{*}$ & $0.0004^{*}$ \\
\hline Temporal lobe & $10(38.5 \%)$ & $19(4.2 \%)$ & $<0.0001^{*}$ & $0.0187^{*}$ \\
\hline Parietal lobe & $11(42.3 \%)$ & $26(5.8 \%)$ & $<0.0001^{*}$ & 0.0610 \\
\hline Occipital lobe & $7(26.9 \%)$ & $14(3.1 \%)$ & $<0.0001^{*}$ & $0.0131^{*}$ \\
\hline Non-lobar hematoma & $4(15.4 \%)$ & $394(87.2 \%)$ & & \\
\hline Putamen & $4(15.4 \%)$ & $158(35.0 \%)$ & 0.0519 & 0.3018 \\
\hline Thalamus & $0(0.0 \%)$ & $160(35.4 \%)$ & 0.9885 & 0.9982 \\
\hline Caudate & $0(0.0 \%)$ & $11(2.4 \%)$ & 0.9893 & 0.9995 \\
\hline Other brain stem & $0(0.0 \%)$ & $21(4.6 \%)$ & 0.9903 & 0.9993 \\
\hline Cerebellum & $0(0.0 \%)$ & $42(9.3 \%)$ & 0.9863 & 0.9991 \\
\hline Removal of hematoma & $7(26.9 \%)$ & $62(13.7 \%)$ & 0.0694 & 0.9723 \\
\hline
\end{tabular}

$* p<0.05$ was considered significant

と関連があり，大脳皮質の微小出血 (microbleeds)などの 微小血管障害(small vessel disease)の関与が示唆されたと 報告している。早期発作は出血発症と時間的に関連して起 こる急性症候性発作であり, 誘発性発作 (provoked seizure) に該当する ${ }^{1)}$ 。てんかんで認められるのは非誘発性 発作 (unprovoked seizure)であり, 急性症候性発作とは機 序が異なる ${ }^{1)}$. 早期発作が後に実際にてんかんに移行する かについては，症例ごとに異なると考えられる．

以上のことを考慮し, 早期発作で開始した抗てんかん薬 を継続するか否かについて, 発作症状の反復や脳波所見な どより症例ごとに慎重に検討する必要があると考えられ る. 入院時に投与された抗てんかん薬が, その後も漫然と 継続されている報告もあり ${ }^{18)}$ ，解決すべき問題点と考えら れる。

\section{4. 晚期発作 (late seizure)}

晚期発作を認めた症例において，84.6\%で発作の反復を 認めた。晚期発作は反復しやすいことが指摘されており 同様の傾向が示された。晚期発作は非誘発性発作であ $り^{1)}$, 容易にてんかんを生じることが示唆されている ${ }^{4)}$. 国際抗てんかん連盟(International League Against Epilepsy：ILAE)が提唱しているてんかんの実用的臨床的定 義では, これまで提唱されている 2 回以上の非誘発性発作 を認める場合だけでなく, 大脳の器質的病変の存在など発 作闇値を持続的に低下させる要因を有している場合は, 1 回の非誘発性発作だけでもてんかんが存在するとされ た ${ }^{10)}$. したがって, 脳出血の晚期発作では, 1 回の発作で
Table 3 Comparison between early and late seizures

\begin{tabular}{lcc}
\hline & Early seizures & Late seizures \\
\hline Seizures & $13(100.0 \%)$ & $13(100.0 \%)$ \\
Recurrent seizures & $2(15.4 \%)$ & $11(84.6 \%)$ \\
\hline
\end{tabular}

もてんかんと診断できると考えられる，実際に発作は反復 しやすく, 初回発作でも治療を開始してよいと考えられ る.なお，晚期発作のみでは症例数が少ないため，今回は 各因子間の差異を示すまではいたらず今後のさらなる検討 が必要である.

\section{結 語}

大脳皮質に及ぶ出血は，てんかん発作の危険因子とな る．血腫除去術はてんかん発作の危険因子とはならず，術 後の抗てんかん薬投与は症例ごとに慎重に検討する必要が ある。早期発作は誘発性発作であり，発作症状反復の有無 や脳波検查などの慎重な観察が必要と考えられる．晚期発 作は非誘発性発作であり，初回発作でもてんかんとして治 療を開始してよいと考えられる。

本論文の要旨は, 第 46 回日本脳卒中の外科学会学術集 会において発表した。

著者全員は日本脳神経外科学会への COI 自己申告を完 了しており，本論文の発表に関して開示すべきCOI はあ りません。 


\section{文献}

1) Beghi E, Carpio A, Forsgren L, et al: Recommendation for a definition of acute symptomatic seizure. Epilepsia 51: 671675,2010

2) Beghi E, D'Alessandro R, Beretta S, et al: Incidence and predictors of acute symptomatic seizures after stroke. Neurology 77: 1785-1793, 2011

3) Biffi A, Rattani A, Anderson CD, et al: Delayed seizures after intracerebral haemorrhage. Brain 139: 2694-2705, 2016

4) Bladin CF, Alexandrov AV, Bellavance A, et al: Seizures after stroke: a prospective multicenter study. Arch Neurol 57: $1617-1622,2000$

5) Claassen J, Jetté N, Chum F, et al: Electrographic seizures and periodic discharges after intracerebral hemorrhage. Neurology 69: 1356-1365, 2007

6) De Herdt V, Dumont F, Hénon H, et al: Early seizures in intracerebral hemorrhage: incidence, associated factors, and outcome. Neurology 77: 1794-1800, 2011

7) De Reuck J, Hemelsoet D, Van Maele G: Seizures and epilepsy in patients with a spontaneous intracerebral haematoma. Clin Neurol Neurosurg 109: 501-504, 2007

8) Faught E, Peters D, Bartolucci A, et al: Seizures after primary intracerebral hemorrhage. Neurology 39: 1089-1093, 1989

9) Ferlazzo E, Gasparini S, Beghi E, et al: Epilepsy in cerebrovascular diseases: review of experimental and clinical data with meta-analysis of risk factors. Epilepsia 57: 1205-1214, 2016

10) Fisher RS, Acevedo C, Arzimanoglou A, et al: ILAE official report: a practical clinical definition of epilepsy. Epilepsia 55: 475-482, 2014
11) Giroud M, Gras P, Fayolle H, et al: Early seizures after acute stroke: a study of 1,640 cases. Epilepsia 35: 959-964, 1994

12) Guidelines for epidemiologic studies on epilepsy: Commission on Epidemiology and Prognosis, International League Against Epilepsy. Epilepsia 34: 592-596, 1993

13) Haapaniemi E, Strbian D, Rossi C, et al: The CAVE score for predicting late seizures after intracerebral hemorrhage. Stroke 45: 1971-1976, 2014

14) Krumholz A, Wiebe S, Gronseth G, et al: Practice Parameter: evaluating an apparent unprovoked first seizure in adults (an evidence-based review): report of the Quality Standards Subcommittee of the American Academy of Neurology and the American Epilepsy Society. Neurology 69: 1996-2007, 2007

15）日本脳卒中学会 脳卒中ガイドライン委員会(編)：脳卒中ガ イドライン 2015. III 脳出血 4. 高血圧性脳出血の慢性期 治療. 東京, 協和企画, 2015, pp153-159

16) Passero S, Rocchi R, Rossi S, et al: Seizures after spontaneous supratentorial intracerebral hemorrhage. Epilepsia 43: 11751180, 2002

17) Rossi C, De Herdt V, Dequatre-Ponchelle N, et al: Incidence and predictors of late seizures in intracerebral hemorrhages. Stroke 44: 1723-1725, 2013

18) Srinivasan S, Shin H, Chou SH, et al: Seizures and antiepileptic drugs in patients with spontaneous intracerebral hemorrhages. Seizure 22: 512-516, 2013

19) Vespa PM, O'Phelan K, Shah M, et al: Acute seizures after intracerebral hemorrhage: a factor in progressive midline shift and outcome. Neurology 60: 1441-1446, 2003

20) Yang TM, Lin WC, Chang WN, et al: Predictors and outcome of seizures after spontaneous intracerebral hemorrhage. $J$ Neurosurg 111: 87-93, 2009 